\title{
Clinical and genetic basis of congenital myasthenic syndromes
}

\author{
Bases clínicas e genéticas das síndromes miastênicas congênitas \\ Paulo Victor Sgobbi de Souzaํ, Gabriel Novaes de Rezende Batistella , Valéria Cavalcante Lino, \\ Wladimir Bocca Vieira de Rezende Pinto ${ }^{1}$, Marcelo Annes ${ }^{1}$, Acary Souza Bulle Oliveira ${ }^{1}$
}

\begin{abstract}
Neuromuscular junction disorders represent a wide group of neurological diseases characterized by weakness, fatigability and variable degrees of appendicular, ocular and bulbar musculature involvement. Its main group of disorders includes autoimmune conditions, such as autoimmune acquired myasthenia gravis and Lambert-Eaton syndrome. However, an important group of diseases include congenital myasthenic syndromes with a genetic and sometimes hereditary basis that resemble and mimick many of the classic myasthenia neurological manifestations, but also have different presentations, which makes them a complex clinical, therapeutic and diagnostic challenge for most clinicians. We conducted a wide review of congenital myasthenic syndromes in their clinical, genetic and therapeutic aspects.
\end{abstract}

Keywords: myasthenia gravis; congenital myasthenic syndromes, genetics.

\section{RESUMO}

Distúrbios da junção neuromuscular representam um grupo amplo de doenças neruológicas caracterizadas por fraqueza, fadigabilidade e graus variados de envolvimento das musculaturas apendicular, ocular e bulbar. Os principais grupos de doenças deste grupo incluem condições auto-imunes, como a miastenia gravis auto-imune adquirida e a síndrome de Lambert-Eaton. Entretanto, um outro grupo importante de doenças incluem as sindromes miastênicas congênitas com uma base genética e eventualmente hereditária que lembra e mimetiza muitas das manifestações neurológicas clássicas das miastenias, mas também se apresentam de diferentes formas tornando um desafio clínico, terapêutico e diagnóstico complexo para a maioria dos clínicos. Realizamos ampla revisão sobre as síndromes miastênicas congênitas em seus aspectos clínicos, genéticos e terapêuticos.

Palavras-chave: miastenia gravis; sindromes miastênicas congênitas, genética.

In 1895, Friedrich Jolly using Greek prefixes for muscle and weakness created the term "myasthenia" and used the Latin word "gravis" to describe the severity of weakness that can often lead patients to death ${ }^{1}$. Myasthenia is described as a clinical group of conditions affecting neuromuscular transmission and can occur in the context of acquired and hereditary congenital conditions.

Congenital myasthenic syndromes (CMS) comprise a heterogeneous group of rare inherited diseases in which the neuromuscular transmission in the motor plate is compromised by one or more genetic pathophysiological specific mechanisms ${ }^{2}$. Congenital myasthenic syndromes can be classified according to the pattern of inheritance, based on the altered protein involved in the motor plate, or by taking into account the site at the neuromuscular junction (pre-synaptic, synaptic, or postsynaptic) involved with the dysfunction (Table 1$)^{3}$.
Although most commonly considered in the differential diagnosis of early-onset hypotonia in the infant and neonate, CMS must be considered in a wide group of clinical and electroneuromyographic scenarios, even including cases with juvenile and adult-onset symptomatology ${ }^{2,3}$. It is essential to consider CMS as an important differential diagnosis, as many presentations represent well-responsive therapeutic forms and different inheritance patterns are involved, emphasizing the crucial role of genetic counseling.

\section{DIAGNOSIS AND CLINICAL FEATURES}

At present there are no well-defined diagnostic criteria for CMS. Congenital myasthenic syndromes should be suspected in cases of: (i) early-onset fatigable muscle weakness mainly

\footnotetext{
${ }^{1}$ Universidade Federal de São Paulo, Departamento de Neurologia e Neurocicurgia, Divisão de Doenças Neuromusculares, São Paulo SP, Brasil.

Correspondence: Wladimir Bocca Vieira de Rezende Pinto; Departamento de Neurologia e Neurocicurgia, Universidade Federal de São Paulo (UNIFESP);

Rua Estado de Israel, 899; 04022-002 São Paulo SP, Brasil. E-mail: wladimirbvrpinto@gmail.com

Conflict of interest: There is no conflict of interest to declare.

Received 09 September 2015; Received in final form 05 March 2016; Accepted 03 May 2016.
} 
Table 1. Classification of congenital myasthenic syndromes (CMS) related to pattern of inheritance and molecular targets at the neuromuscular junction.

\begin{tabular}{|c|c|}
\hline \multicolumn{2}{|l|}{ I. Pattern of inheritance } \\
\hline Autosomal dominant (gain-of-function) & Slow-channel syndrome, SNAP25B*, SYT2* \\
\hline Autosomal recessive (loss-of-function) & All other subtypes \\
\hline \multicolumn{2}{|c|}{ II. Site of defect and molecular targets at the neuromuscular junction } \\
\hline Presynaptic defects & ChAT deficiency, SNAP25B deficiency, synaptotagmin-2 deficiency \\
\hline Acetylcholine receptor defects & $\begin{array}{l}\text { Primary deficiency, slow-channel syndrome (CHRNA1, CHRNB, CHRND, CHRNE, CHRNG), } \\
\text { fast-channel syndrome (CHRNA, CHRND, CHRNE) }\end{array}$ \\
\hline Synaptic basal lamina defects & Acetylcholinesterase deficiency (ColQ), $\beta 2$-laminin deficiency \\
\hline $\begin{array}{l}\text { Endplate development and maintenance } \\
\text { congenital defects }\end{array}$ & $\begin{array}{l}\text { Agrin deficiency, MuSK deficiency, LRP4 deficiency, Dok-7 deficiency, rapsyn deficiency, } \\
\text { COL13A1 mutations }\end{array}$ \\
\hline Metabolic and mitochondrial disorders & Congenital disorders of glycosylation, SLC25A1 gene mutations \\
\hline Others & $\begin{array}{l}\text { Congenital myopathies with secondary neuromuscular transmission compromise (MTM1, } \\
\text { RYR1, DNM2, TPM3, BIN1); PREPL deletion; plectin deficiency }\end{array}$ \\
\hline
\end{tabular}

*extremely rare presentations.

involving ocular, bulbar and proximal limb musculature (generally varying from birth to late childhood); (ii) a positive family history of a specific disorder or sometimes only the history of a hypotonic infant; (iii) clinical and neurophysiological myasthenic findings with a negative antibody testing profile; (iv) electromyography (EMG) studies showing decremental responses of $10 \%$ or more in the amplitude or in the quarter of the area from the first evoked compound motor action potential (CMAP), or single-fiber EMG studies compatible with a neuromuscular junction dysfunction; and (v) the presence of a specific clinical syndromic phenotype (i.e. Escobar syndrome, Pierson syndrome) $)^{2,3,4}$.

However, in some congenital myasthenic syndromes, the onset of clinical manifestations may be late with involvement in adolescence or adulthood, other family members may not have been affected by the disease and electromyography changes may not be present in all muscles or occur intermittently ${ }^{4}$. Therefore, although some clinical, therapeutic and neurophysiological clues allow a high clinical suspicion for each CMS subtype (Tables 2 and 3), in many cases of rapsyn deficiency, primary deficiency of endplate acetylcholine receptor and fast-channel syndrome, there are frequently no specific hallmarks in presentations ${ }^{2,3,4}$.

The list of differential diagnoses of CMS is huge and includes some of the following conditions: congenital myopathies, congenital muscular dystrophy, limb-girdle muscular dystrophy, mitochondrial myopathies, facioscapulohumeral dystrophy, myotonic dystrophy and autoimmune myasthenia gravis, motor neuron disease and peripheral neuropathies (Table 4) 2 .

\section{Epidemiology}

The prevalence of CMS is very difficult to estimate due to the clinical variability of cases and the fact that many cases have no specific etiologic diagnosis or are undiagnosed. Since they are rare medical conditions in which definite diagnosis rests on clinical, electromyography and specific genetic testing, few data are available. Furthermore, there are few series of patients where this complete diagnostic profile has been established, and most of the current knowledge has been obtained by reports of isolated case reports. ${ }^{4}$.

A study in the UK estimated that the prevalence of CMS with a defined genetic diagnosis is approximately 9.2 cases per million children under 18 years old in the population ${ }^{5}$. There are also some ethnic variations in the genetic diagnosis of CMS with some mutations being more common in some populations, such as the 1293insG mutation in the gene CHRNE coding the epsilon subunit of the acetylcholine receptor, more frequently found in families from north Africa $^{6}$, and the $1267 \mathrm{delG}$ mutation also in the CHRNE in gypsy families from southeast Europe ${ }^{7}$.

An important epidemiological profile on CMS was obtained in a study performed at the Mayo Clinic. Most cases occured as a consequence of postsynaptic defects (68\%), and basal lamina defects (13.7\%), development and maintenance of the end plate defects (12.5\%), pure presynaptic defects (5.9-8\%) and congenital myopathies with secondary neuromuscular junction transmission defects $(0.3 \%)$ also represent other rare congenital myasthenic syndromes. Thus, postsynaptic forms represent up to $75-80 \%$ of all CMS cases ${ }^{3,4,8}$. In southern Brazil, in the state of Paraná, a minimum prevalence of 0.18/100.000 of CMS is estimated'.

\section{Pathophysiology}

To understand the pathophysiological mechanisms involved in CMS, it is essential to recognize key aspects of the neuromuscular junction structure and function. The neuromuscular junction has three basic components: (i) the presynaptic nerve terminal, where there is the biosynthesis process, storage and release of acetylcholine, the main neurotransmitter involved in primary muscular contraction process; (ii) the synaptic space or synaptic cleft, where acetylcholine is released by the presynaptic nerve terminal and where there is a complex network of local proteins responsible for maintenance of the structure of the neuromuscular junction; and (iii) the postsynaptic muscle membrane, where there are acetylcholine receptors responsible for the action potential deflagration, endplate 
Table 2. Main diagnostic clues to guide differential diagnosis of congenital myasthenic syndromes (CMS) subtypes. 2,4

\begin{tabular}{|c|c|}
\hline \multicolumn{2}{|l|}{ I. Clinical clues of CMS subtypes } \\
\hline $\begin{array}{l}\text { Early-onset phenotypes (neonatal, lactancy, } \\
\text { early infancy) }\end{array}$ & $\begin{array}{l}\text { ChAT deficiency, synaptotagmin-2 deficiency, acetylcholinesterase, slow-channel } \\
\text { syndrome, fast-channel syndrome, agrin deficiency, LRP4 deficiency, MuSK deficiency, } \\
\text { Dok-7 deficiency, rapsyn deficiency, GFPT1, ALG2, ALG14, GMPPB, PREPL deficiency, } \\
\text { plectin deficiency, SCN4A, COL13A1 }\end{array}$ \\
\hline $\begin{array}{l}\text { Late-onset phenotypes (late infancy, } \\
\text { adolescence, juvenile, adult) }\end{array}$ & $\begin{array}{l}\text { Acetylcholinesterase deficiency (variants), slow-channel syndrome, } \\
\text { agrin deficiency, SCN } 4 A\end{array}$ \\
\hline LGMD-like phenotype & GFPT1, LRP4 deficiency, plectin deficiency \\
\hline Apneic episodes & ChAT deficiency, SCN $4 A$ \\
\hline Laryngeal stridor and vocal cord palsy & Dok-7 deficiency \\
\hline Epilepsy with intellectual disability & DPAGT1 deficiency \\
\hline Cerebellar ataxia & SNAP25B \\
\hline Pupillary defects & ColQ mutations \\
\hline Ptosis & $\begin{array}{l}\text { Primary AChR deficiency, Dok-7 deficiency, SNAP25B, agrin deficiency, MuSK } \\
\text { deficiency, rapsyn deficiency, PREPL, congenital myopathies, COL13A1 }\end{array}$ \\
\hline Ophthalmoparesis ( \pm strabismus) & $\begin{array}{l}\text { Rapsyn deficiency, primary AChR deficiency, MuSK deficiency, Dok-7 deficiency, } \\
\text { congenital myopathies }\end{array}$ \\
\hline Facial palsy & $\begin{array}{l}\text { Agrin deficiency, MuSK deficiency, Dok-7 deficiency, rapsyn deficiency, PREPL, } \\
\text { congenital myopathies }\end{array}$ \\
\hline Cervical weakness & Slow-channel syndrome, Dok-7 deficiency, COL13A1 \\
\hline $\begin{array}{l}\text { Arthrogryposis multiplex congenital-like } \\
\text { phenotype and early-onset joint contractures }\end{array}$ & $\begin{array}{l}\text { Rapsyn deficiency, ChAT deficiency, AChR deficiency (CHRND, CHRNG), SNAP25B, } \\
\text { synaptotagmin-2 }\end{array}$ \\
\hline Dysmorphic features & Rapsyn deficiency, $\beta 2$-laminin deficiency, COL13A1 \\
\hline Congenital malformations & $\begin{array}{l}\text { Pierson syndrome ( } \beta 2 \text {-laminin: ocular malformation, congenital nephrosis); rapsyn } \\
\text { deficiency; GFPT1 deficiency; SLC25A1 (optic nerve hypoplasia, corpus callosum } \\
\text { agenesis) }\end{array}$ \\
\hline Anoxic encephalopathy-like phenotype & Rapsyn deficiency, SCN4A \\
\hline Epidermolysis bullosa simplex & Plectin deficiency \\
\hline \multicolumn{2}{|l|}{ II. Histopathological clues of CMS subtypes } \\
\hline $\begin{array}{l}\text { Tubular aggregates in the sarcoplasmic } \\
\text { reticulum }\end{array}$ & GFPT1, DPAGT1 and ALG2-related CMS subtypes \\
\hline Vacuolar autophagic myopathy & GFPT1 and DPAGT1-related subtypes \\
\hline
\end{tabular}

potential and the acetylcholinesterase enzyme, involved with the breakdown of acetylcholine and subsequent restoration of the resting potential of the membrane postsynaptic potential $^{8,10,11,12}$. Mutations in the genes encoding proteins related to any one of these three components of the neuromuscular junction could give rise to different CMS phenotypes.

Currently, major defects involved in the etiology of CMS occur $^{2,4}$ : (A) in the presynaptic terminal; (B) associated with the synaptic basal lamina membrane; $(\mathrm{C})$ the acetylcholine receptor; (D) shortcomings in the maintenance and development of the neuromuscular junction; (E) congenital defects in glycosylation; and (F) other sites and mechanisms (Figure).

\section{Clinical and genetic basis of congenital myasthenic syndromes}

Currently, more than 20 different genes are involved as monogenic causes of CMS, with an increasing number of new discoveries every year driven by next-generation sequencing with complete exome sequencing (whole-exome sequencing). This has clarified the pathophysiological mechanisms of this spectrum of disorders, not restricted to the neuromuscular junction structures and pointing to new opportunities and approaches for future therapeutic modalities ${ }^{4,13,14}$.

\section{PRE-SYNAPTIC SYNDROMES}

\section{Deficiency of choline acetyltransferase (ChAT) (OMIM \#254210)}

Presynaptic defects represent less than $6 \%$ of all CMS cases. The enzyme choline acetyltransferase (encoded by the CHAT gene, 10q11.23), located in the presynaptic terminal region of the axon of the lower motor neuron, is involved in the biosynthesis of the neurotransmitter acetylcholine from acetyl-coenzyme A (acetyl-CoA) and cho$\operatorname{line}^{2,4}$. The severity of ChAT deficiency depends on the type and site of mutation affecting the enzyme structure, the 
Table 3. Therapeutic clues in the differential diagnosis of congenital myasthenic syndromes (CMS) subtypes ${ }^{2,4}$.

\begin{tabular}{|c|c|}
\hline Quinidine-responsive phenotype & Slow-channel syndrome \\
\hline Fluoxetine-responsive phenotype & Slow-channel syndrome \\
\hline Acetazolamide-responsive phenotype & Sodium channel \\
\hline $\begin{array}{l}\text { Amifampridine-responsive phenotype } \\
\text { (3,4-diaminopyridine) }\end{array}$ & $\begin{array}{l}\text { Primary AChR deficiency, SNAP25, fast channel syndrome, MuSK, rapsyn, } \\
\text { ALG2, ALG14, GFPT1, DPAGT1, COL13A1 }\end{array}$ \\
\hline Albuterol-responsive phenotype & $\begin{array}{l}\text { Dok-7, Primary AChR deficiency, MuSK (partial), acetylcholinesterase } \\
\text { deficiency }\end{array}$ \\
\hline Salbutamol-responsive phenotype & $\begin{array}{l}\text { Rapsyn, acetylcholinesterase, primary AChR deficiency, MuSK, DPAGT1 } \\
\text { (partial), COL13A1 }\end{array}$ \\
\hline Ephedrine-responsive phenotype & Laminin- $\beta 2$ deficiency, agrin, acetylcholinesterase, Dok-7 \\
\hline Pyridostigmine-responsive phenotype & $\begin{array}{l}\text { GFPT1, sodium channel (SCN4A), centronuclear congenital myopathy, ChAT } \\
\text { deficiency, fast-channel syndrome, AChR deficiency, paucity of synaptic } \\
\text { vesicles and reduced quantal release (partial), congenital myopathies } \\
\text { (partial: centronuclear myopathy), PREPL (transient) }\end{array}$ \\
\hline Pyridostigmine-avoidance phenotype (clinical worsen) & $\begin{array}{l}\text { Acetylcholinesterase deficiency, Laminin- } \beta 2 \text { deficiency, slow-channel } \\
\text { syndrome, LRP4, Dok-7 and MuSK deficiencies; agrin deficiency }\end{array}$ \\
\hline Amifampridine-avoidance phenotype (clinical worsen) & Acetylcholinesterase deficiency, slow channel syndrome, LRP4 mutations \\
\hline Fluoxetine-avoidance phenotype (clinical worsen) & Fast channel syndrome \\
\hline Quinidine-avoidance phenotype (clinical worsen) & Fast channel syndrome \\
\hline Clinical refractory phenotype & $\begin{array}{l}\text { Plectin deficiency (pyridostigmine, amifampridine), laminin- } \beta 2 \text {, plectin, } \\
\text { acetylcolinesterase (pyridostigmine), DPAGT1 (partial), GMPPB }\end{array}$ \\
\hline
\end{tabular}

Table 4. Main differential diagnosis of congenital myasthenic syndromes (CMS) of early- and late-onset presentations.

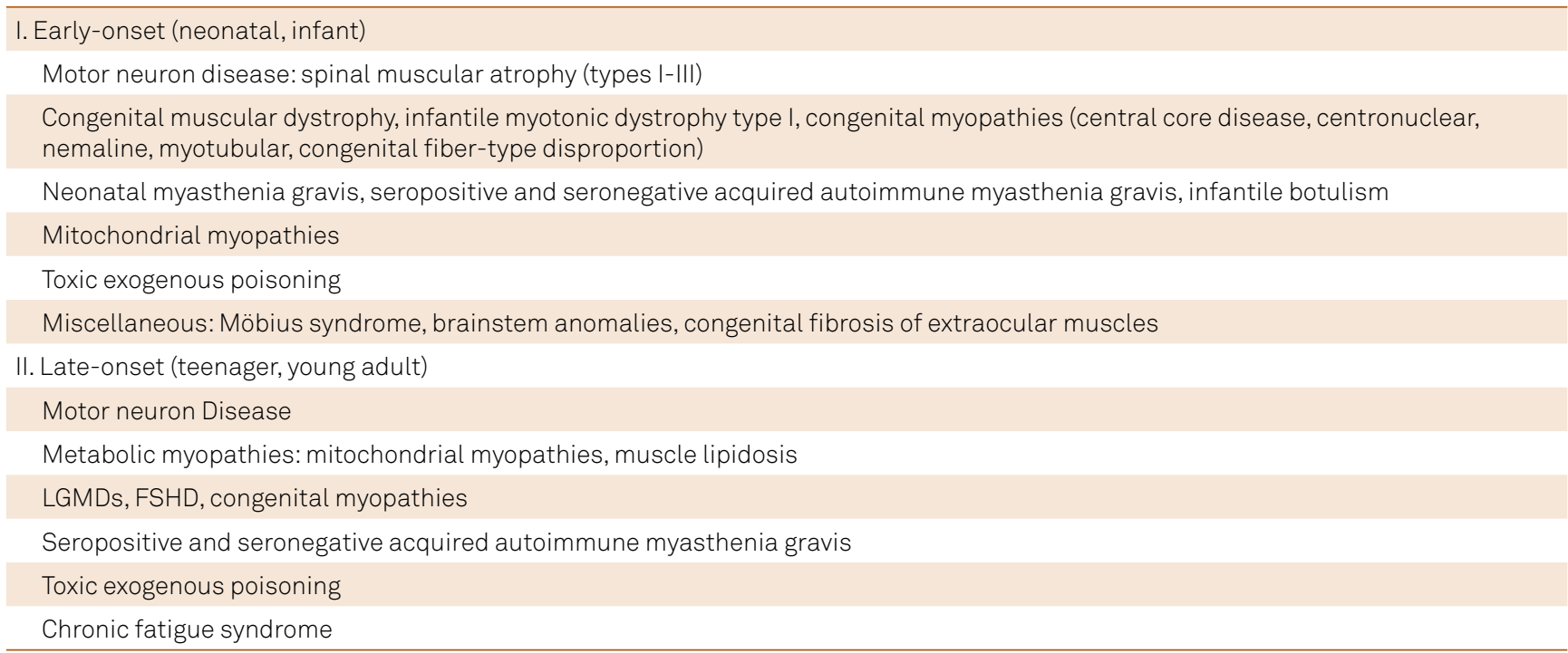

FSHD: facioscapulohumeral muscular dystrophy; LGMD: limb-girdle muscular dystrophy ${ }^{2,4}$.

most severe clinical manifestations being found in mutations that affect the catalytic domain of the enzyme or the binding site to the substrate ${ }^{2,4,8}$.

Mutations in the CHAT gene produce a classical CMS phenotype with early onset in the neonatal period and associated with serious and threatening episodes of apnea ${ }^{2,3,4}$. Episodes of apnea may have abrupt onset and can be triggered after episodes of physical or emotional stress or illnesses in patients with few or no prior myasthenic symptoms ${ }^{2,15,16}$. Variable ptosis without ophthalmoparesis is common. Some patients may present with apnea and marked hypotonia at birth with difficulty in maintaining spontaneous breathing and they can also develop secondary brain atrophy due to hypoxemia in the neonatal period, while other patients are normal at birth and rarely begin to manifest apneic episodes during childhood or early adolescence. Recurrent acute attacks of respiratory failure lasting for weeks have also been described. Severe presentations with arthrogryposis multiplex-like phenotype have also been described ${ }^{2,15,16}$. 


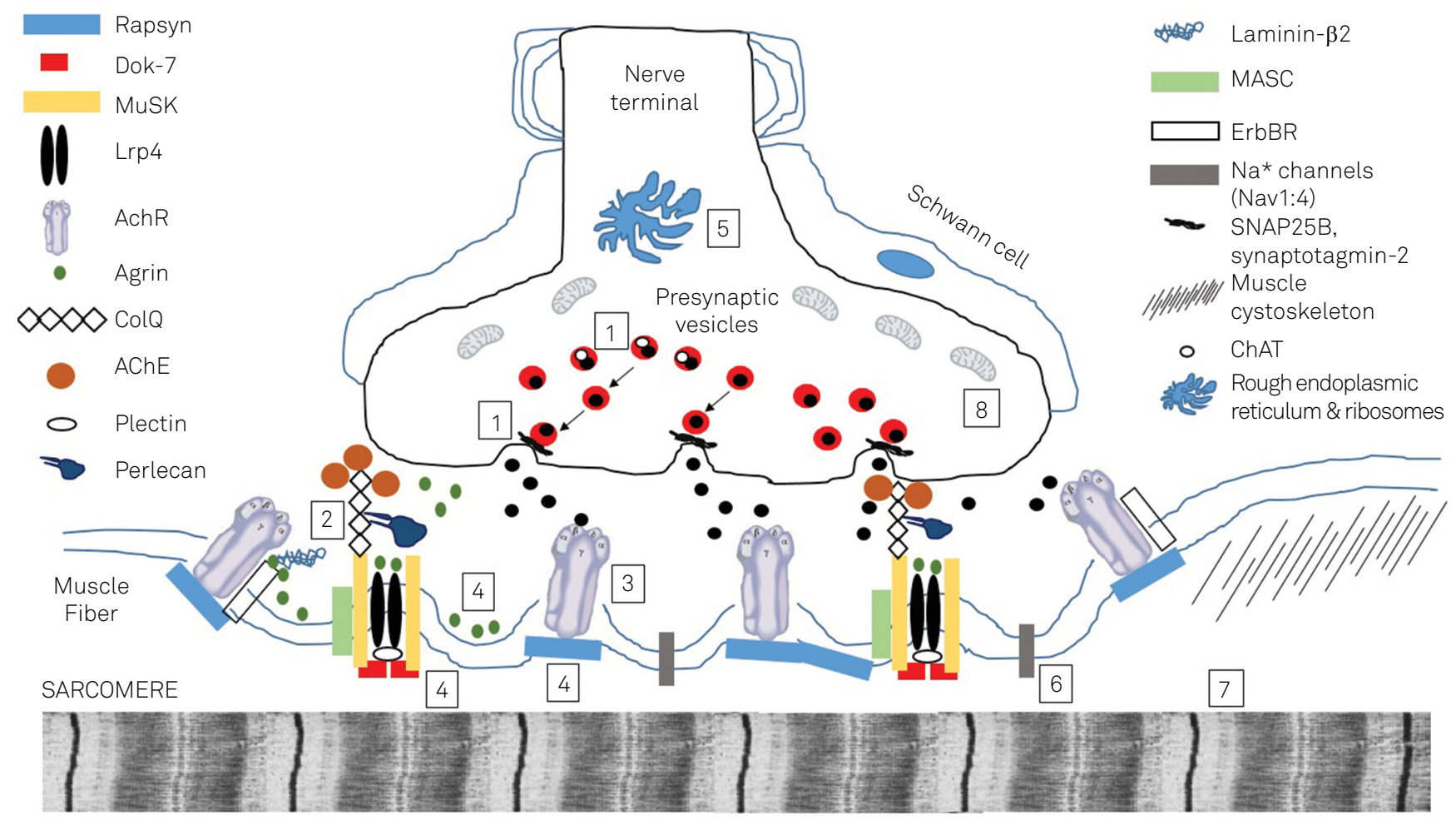

Figure. Representation of the main pathophysiological mechanisms involved in different forms of CMS: (1) acetylcholine biosynthesis defects and vesicular transport and fusion defects; (2) acetylcholinesterase deficiency; (3) acetylcholine receptor defects; (4) agrin deficiency; (5) congenital disorders of glycosylation; (6) channelopathies; (7) congenital myopathies with secondary neuromuscular transmission defects; and (8) mitochondrial dysfunction. Legends: ChAT: choline acetyltransferase; ErbBR: epidermal growth factor receptor; MASC: muscle-associated specificity component; AChE: acetylcholinesterase; Lrp4: low-density lipoprotein receptor-related protein 4; ColQ: collagen-like tail subunit or acetylcholinesterase-associated collagen; MuSK: muscle-specific tyrosine kinase receptor; Dok-7: downstream of tyrosine kinase $7^{2,3,4}$.

An indicator to consider CMS by mutations in the CHAT gene is the presence of a decrease in the amplitude of the CMAP associated with a potential endplate $50 \%$ below the baseline (normal decrease is less than $30 \%$ ) followed by a very slow recovery 5-10 minutes after subtetanic stimulation². CMAP amplitude decrease is not a pathognomonic finding of ChAT deficiency, being present in other CMS. However, the recovery is usually complete in less than five minutes. ${ }^{2,4}$ In such cases, the amplitudes of the CMAP, endplate potential and miniature endplate potentials are normal at rest, decreasing after a repetitive stimulation test at $10 \mathrm{~Hz}$ for five minutes and marked reduction of CMAPs with slow recovery to the basal line in 10 to 15 minutes $^{3}$.

\section{Deficiency of SNAP25B (OMIM \#616330)}

The proteins of the SNARE class (soluble N-ethylmaleimidesensitive factor attachment protein receptors) constitute the core of the intracellular machinery of fusion of synaptic vesicles $^{17}$. SNAP25 (synaptosomal-associated protein $25-\mathrm{Kd}$, encoded by the SNAP25 gene, 20p12.2) and the protein syntaxin bind to target cell membranes and are termed t-SNAREs, which have an important role in protein and vesicles anchoring, initiation of intracellular vesicles and the rapid triggering the exocytosis process ${ }^{17}$.
Deficiency of SNAP25B was reported with an autosomal dominant pattern of CMS presenting in an 11-year-old African-American female patient with a history of intrauterine hypotonia, cyanosis at birth, delayed psychomotor development, multiple joint contractures, muscle weakness, fatigable ptosis, associated with ataxia and early childhood epilepsy, whose biomolecular studies revealed a decrease in the amount of acetylcholine released from the presynaptic nerve terminal from each motor nerve impulse $\mathrm{e}^{4,18}$.

\section{Deficiency of synaptotagmin-2 (OMIM \#616040)}

Synaptotagmin-2 protein is a synaptic vesicle protein that acts as a calcium sensor during the neuromuscular transmission process. ${ }^{19}$ Mutations have been described in two families with a motor neuropathy phenotype characterized by hollow feet and hammer toes with diminished or abolished reflexes associated with a fatigability of proximal and distal muscles with weakness. Electromyography tests demonstrated low amplitude CMAP with a marked increase in the amplitude of the CMAP after performing a fast exercise, mimicking the findings of Lambert-Eaton myasthenic syndrome $^{2,20}$. This presentation has been linked to autosomal dominant inheritance presentations of CMS linked to SYT2 gene (1q32.1). 


\section{SYNDROMES ASSOCIATED WITH THE SYNAPTIC BASAL LAMINA}

\section{Deficiency of endplate acetylcholinesterase by mutations in COLQ (OMIM \#603034)}

The acetylcholinesterase in the neuromuscular plate is an asymmetrical enzyme which may be constituted by one, two or three catalytic subunits tetramers that are anchored in the basal membrane with a triple-stranded collagen tail called ColQ (acetylcholinesterase-associated collagen). Mutations in the COLQ gene (3p25.1) promote a prolongation of the residence time of acetylcholine in the neuromuscular junction, producing a desensitization of muscle acetylcholine receptor and a secondary myasthenic syndrome ${ }^{21,22}$. This presentation corresponds to $13,4 \%$ of all CMS cases ${ }^{3}$.

The clinical picture begins at birth or in early childhood as an autosomal recessive CMS, characterized by progressive muscle weakness affecting all voluntary muscles and can spare the extrinsic ocular muscles. There is a direct correlation of site of mutations and clinical presentations and course. Most cases associated with C-terminal mutations have a light clinical course and late-onset of symptoms. Most cases related to N-terminal mutations or rod-domain of ColQ have early-onset severe presentations. Diagnosis is essential as genetic counseling represents an important clinical step and as some cases present good clinical responses to the use of albuterol or ephed$\operatorname{rin}^{21,22}$. Electrophysiological studies typically confirm the presence of a decremental response pattern of the repetitive CMAPs greater than $10 \%^{23}$.

\section{Deficiency of laminin- $\beta 2$ (OMIM \#609049)}

Laminin- $\beta 2$ protein is encoded by the $L A M B 2$ gene (3p21.31) and expressed in the basal lamina of the endplate terminal of the neuromuscular junction in the eyes and kidneys participating in the differentiation process of the pre-synaptic region as well as the alignment of the presynaptic motor terminal with the post-synaptic region in the muscle membrane ${ }^{3}$. Only one case has been reported of autosomal recessive congenital myasthenic syndrome resulting from deficiency of laminin- $\beta 2$ (less than $0,5 \%$ of all CMS cases) in a 20-year-old female patient with eye and kidney malformations, compatible with Pierson syndrome or microcoria-congenital nephrotic syndrome. Classically it represents a pyridostigmine-refractory form of CMS with predominant proximal limb weakness, where ocular abnormalities (including nonreactive fixed narrowing of the pupils, hypoplasia of the iris and the ciliary body, and lenticonus posterior) and congenital kidney disease (including neonatal-onset congenital nephrotic syndrome, early-onset end-stage renal disease and diffuse mesangial sclerosis) represent major cardinal signs. Another allelic presentation may be as hereditary nephrotic syndrome type 5 (MIM \#614199) $)^{2,24}$.

\section{Defects of the acetylcholine receptor}

The nicotinic acetylcholine receptor is a pentameric complex comprising four transmembrane subunits, composed of $\alpha 2 \beta \delta \varepsilon$ in the adult neuromuscular plate and $\alpha 2 \beta \delta \gamma$ in the fetal neuromuscular plate, as well in extrajunctional regions $^{2,4}$. The genes encoding the $\alpha$ (CHRNA1 gene, 2q31.1), $\delta(C H R N D$ gene, 2q37.1) and $\gamma(C H R N G$ gene, 2q37.1) chains are located on the long arm of chromosome 2 at different genetic loci, while the genes encoding the $\beta$ chain (CHRNB1 gene) and $\varepsilon$ (CHRNE gene) are located in different loci on the short arm of chromosome 17p13.2, $2^{2,4}$ In southern Brazil, as a consequence of founder effect mutations of Hispanic settlers origin, CHRNE gene recessive mutations represent the main cause of CMS 9 .

Mutations in genes encoding the acetylcholine receptor subunits can produce CMS by means of three mechanisms: (1) reducing the number of acetylcholine receptors in the postsynaptic membrane; (2) extended opening called the slow-channel syndrome; (3) short opening of the receptors known as the fast-channel syndrome. ${ }^{2,4}$

\section{Primary deficiency of the acetylcholine receptor}

Primary deficiency of the acetylcholine receptor represents the most common form of CMS (34 to $50 \%$ of all cases) and results from mutations in genes coding any of the subunits of the acetylcholine receptor, with those related to the $\varepsilon$ subunit being the most common and severe ${ }^{2,4}$. The clinical picture is characterized by ptosis, refractory marked ophthalmoparesis and severe muscle weakness of the limbs. There is generally a partially responsive pattern to pyridostigmine, amifampridine and albuterol use in clinical practice ${ }^{2,4,25}$. Mutations in both alleles of CHRNA1, CHRNB or CHRND genes are usually incompatible with life, resulting in death in the fetal period ${ }^{2,4,25}$.

\section{Slow-channel syndrome}

Slow-channel syndrome is part of the kinetic defects of the acetylcholine receptor due to dominant mutations in the domains or pore receptor ligands of the receptorbinding portion. It resembles, in many aspects, the acetylcholinesterase deficiency. This typically presents with symptoms in the first decade of life with prominent and severe involvement of the scapular, cervical and dorsal forearm (wrist and finger extensors) muscle groups, sparing extrinsic ocular muscles and only exceptionally presenting with mild asymmetric ptosis ${ }^{2,26,27}$. Atypical late-onset presentations have also been described as mimicking generalized autoimmune myasthenia gravis with associated mild late-onset myopathic changes and rarely with mild to moderately raised serum creatine kinase levels. However, the good therapeutic response profile to fluoxetine and quinidine and unresponsiveness to amifampridine and pyridostigmine distinguishes this condition from acquired forms ${ }^{26,27,28}$. 


\section{Fast-channel syndrome}

Fast-channel syndrome arises from autosomal recessive mutations in different domains of the acetylcholine receptor subunits and clinically mimicks a typical autoimmune acquired myasthenia gravis starting in the first decade of life with good clinical response to treatment with pyridostigmine and amiframpidine. Fluoxetin and quinidine use must be avoided. Allelic conditions include the multiple pterygium syndrome (lethal type) ${ }^{2,3,29}$.

\section{Defects in the development and maintenance of the endplate}

Congenital myasthenic syndromes can arise by the effect of mutations in genes related to the development and maintenance of the endplate, including $A G R N$ (agrin; 1p36.33), MUSK (9q31.3), LRP4 (11p11.2), DOK7 (4p16.3), RAPSN (11p11.2) and COL13A1 (10q22.1) genes. The agrin protein is secreted in the terminal nerve synaptic cleft and binds to the LRP4 (low density lipoprotein receptorrelated protein 4) protein of the postsynaptic membrane, originating a secondary complex that activates a MuSK (muscle skeletal receptor tyrosine kinase) receptor with tyrosine kinase activity, allowing the phosphorylation of Dok-7 (downstream of tyrosine kinase 7) and rapsyn activation (Figure). Thus, modulatory effects occur and the concentration of acetycholine in the postsynaptic membrane receptor alters the expression of nuclear genes related to the differentiation of the endplate and promoting the maintenance of the postsynaptic membrane $e^{1,2}$.

\section{Agrin deficiency (OMIM \#615120)}

Agrin is a proteoglycan secreted in the synaptic basal laminae by the terminal nerve, phosphorylating and activating MuSK by the LRP4 receptor. Mutations of the AGRN (1p36.33) gene, coding agrin, originates a typical late-onset CMS phenotype starting between the fourth and fifth decades of life and an early-onset variant in infants and neonates. The typical form originates ptosis and mild weakness in the face and proximal limbs weakness, starting from childhood and resulting from homozygous missense mutations (Gly1709Arg) and other types with more severe phenotypes (Gln353X and Val1725Phe). The subtype of early-onset CMS relates to generalized amyotrophy in lower limbs and slowly progressive weakness with lipossubstitution of the posterior compartment of the leg, sparing cranial nerves and axial muscles and without ophthalmoparesis (despite ptosis being frequently found). There is a good response to the use of ephedrine and generally failure to the use of amifampridine and pyridostigmine $e^{3,30,31}$.

\section{LRP4 deficiency (OMIM \#616304)}

The LRP4 deficiency was described in a 14-year-old patient with neonatal respiratory failure, delayed motor development and muscle weakness and fatigability of pelvic and shoulder girdle musculature. The clinical phenotype results from missense mutations Glu1233Lys and Arg1277His. Allelic conditions include sclerosteosis type 2 and Cenani-Lenz syndactyly syndrome $\mathrm{e}^{2,32}$.

\section{MuSK deficiency (OMIM \#616325)}

The MuSK deficiency is extremely rare, results from mutations of the MUSK gene (9q31.3) and manifests through respiratory failure with neonatal ptosis or in the infant with proximal appendiceal involvement, facial and ocular and bulbar variable ${ }^{33}$. MuSK is involved in end-plate maturation and maintenance processes, and aids rapsyn proper function and its complex interactions with AChR in the postsynaptic membrane. The allelic condition is the fetal akinesia deformation sequence ${ }^{2,33}$.

\section{Dok-7 deficiency (OMIM \#254300)}

Dok-7 deficiency represents less than $10 \%$ of all CMS cases. It represents the second most common cause of CMS in southern Brazil9. Different mutations have been described in the DOK7 gene (4p16.3), the most common being the c.1124_1127dupTGCC mutation related to autosomal recessive CMS. The clinical spectrum is very wide, occurring with wrist weakness and lower cervical and facial involvement and some forms with bulbar and ophthalmoparesis involvement. It represents an important differential diagnosis of limb-girdle muscular dystrophies (LGMD) and initiates predominance of type 1 fibers, atrophy of type 2 fibers, and "target" fiber formations ${ }^{34,35}$. An LGMD-like pattern of weakness, ptosis and mild facial weakness with moderate to severe bulbar symptoms and laryngeal stridor and vocal cord palsy occurs in mutations of the last codon. Other cases present as lower limb dominant progressive amyotrophy. Muscle biopsy discloses generally unspecific findings. Clinical worsening is common after pyridostigmine use and clinical improvement frequently observed after ephedrine, salbutamol and albuterol use $\mathrm{e}^{34,35,36}$.

\section{Rapsyn deficiency (OMIM \#616326)}

Rapsyn (receptor-associated protein of the synapse, 43-Kd) deficiency results from homozygous mutations in the RAPSN gene (11p11.2) and represents around 15\% of all CMS cases. This autosomal recessive CMS manifests most commonly in infants during the first year of life (rarely in scholars and young adults), the most common pattern in one third of patients being an arthrogryposis phenotype at birth, multiple congenital contractures and other congenital malformations, frequently in the context of patients with post-anoxic encephalopathy after myasthenic crisis due to infectious complications ${ }^{2,3,4}$. It is remarkable that normal adduction and abduction of the eye with strabismus and ophthalmoparesis is found in less than $25 \%$ of cases. There is some regional segregation of mutations in India and Europe (Asn88Lys mutation). 
Another important finding relates to clinical-genetic correlations: the c.38A $>\mathrm{G}$ mutation presents with a milder phenotype with ptosis, prognathism, facial and masticatory muscle weakness and nasal voice; the N88K mutation represents most neonatal and early-infancy-onset cases; A38G mutation commonly presents with ptosis, hypernasal speech, facial weakness and prominent masticatory dysfunction ${ }^{37}$. The allelic condition leads to to fetal akinesia deformation sequence. Thus, the presence of an early-onset phenotype mimicking chonic nonprogressive hypoxic-ischaemic clinical findings with neuromuscular junction dysfunction signs should raise the possibility of rapsyn deficiency.

\section{COL13A1-related CMS (OMIM \#616720)}

A new autosomal recessive very early-onset CMS has been recently described resulting from homozygous mutations in the COL13A1 gene (10q22.1), coding the alpha-1 chain of the nonfibrillar transmembrane collagen type XIII, involved in autocrine control of the development and maturation of the neuromuscular junction ${ }^{38}$. Clinical presentation is broad and includes ptosis, proximal and distal limb hypotonia, delayed motor milestones, poor head control, feeding difficulties, childhood-onset spinal rigidity, respiratory insufficiency, dyspnea on exertion with exercise intolerance, dysphagia, gastroesophageal reflux and recurrent lower respiratory tract infections. Mild dysmorphic features have also been reported, including pes cavus without early joint contractures, low-set ears, micrognathia, high-arched palate and pectus carinatum. Neurophysiological studies show significant decremental response on repetitive nerve stimulation testing ${ }^{38}$.

\section{Congenital disorders of glycosylation}

Congenital disorders of glycosylation (CDGs) relate to different systemic and neurometabolic syndromes with different congenital malformations, subtypes of congenital muscular dystrophy and congenital myasthenic syndromes by mutations in the genes encoding the enzymes GFPT1 (glutamine:fructose-6-phosphate amidotransferase 1, 2p13.3), DPAGT1 (dolichyl-phosphate UDP-N-acetylglucosamine N-acetylglucosamine-1-phosphotransferase, 11q23.3) ALG2 (alpha-1,3-mannosyltransferase, 9q22.33) and ALG14 (UDP-Nacetylglucosaminyltransferase, 1p21.3). The histopathological presence of muscle tubular aggregates in the setting of characteristic neurophysiological findings in pre- and postsynaptic impaired neuromuscular junction must indicate genetic evaluation for CDG-related $\mathrm{CMS}^{2,3}$. Recently, a fifth glycosylation gene called GMPPB (GDP-mannose pyrophosphorylase $\mathrm{B}, 3 \mathrm{p} 21.31$ ) has also been linked to new CMS phenotypes ${ }^{39}$.

\section{GFPT1 deficiency (OMIM \#610542)}

The GFPT1 (glutamine:fructose-6-phosphate amidotransferase-1) enzyme regulates glucose entering in the hexosamine pathway for the formation of precursor components for processes of O-linked and N-linked glycosylation of basic proteins. Mutations in the GFPT1 gene (2p13.3) represents less than 3\% of all CMS cases. Typically, disability originates slowly progressive muscle weakness with an LGMD-like phenotype responsive to pyridostigmine use and tubular aggregates of sarcoplasmic reticulum in muscle biopsy. Some variants showed multiple arthrogryposis at birth, slow progression until eight years old with severe dysphagia and severe myopathy with autophagic vacuoles in muscle specimens. Ptosis and respiratory insufficiency are rarely found. Raised serum CK is found in around $25 \%$ of cases $^{2,3,40}$.

\section{Deficiency of DPAGT1 (OMIM \#614750)}

TheenzymeDPAGT1(dolichyl-phosphateN-acetylglucosamine phosphotransferase) catalyzes the first step in glycosylation of $\mathrm{N}$-linked proteins. The resulting clinical spectrum of mutations in the DPAGT1 (11q23.3) gene initiates moderate or severe muscle weakness and cognitive impairment, with a therapeutic profile unresponsive to pyridostigmine and amifampridine, and partially responsive to salbutamol. The most common mutations involve His375Tyr and Val264Met. Allelic conditions include CDG type Ij. Muscle biopsy shows small tubular aggregates, fiber type disproportion with small caliber type 1 fibers and autophagic vacuolar myopathy, resembling similar patterns to STIM1-related myopathies ${ }^{3,41,42}$.

\section{ALG2 and ALG14 deficiencies (OMIM \#616228; OMIM \#616227)}

The ALG2 (asparagine-linked glycosylation 2) enzyme participates directly in the second and third steps of $\mathrm{N}$-glycosylation. ALG14 forms a complex with the multiglucosyltransferase ALG13. DPAGT1 participates indirectly in the first step of $\mathrm{N}$-glycosylation. Both syndromes arising from ALG2 (9q22.33) and ALG14 (1p21.3) genes mutations have an early-onset LGMD-like CMS starting in the preschooler with typical myasthenic syndrome complaints. ALG14 deficiency presents with a similar pattern to ALG2-related CMS, despite the absence of tubular aggregates in muscle biopsy. Pyridostigmine may benefit some patients. Allelic conditions include CDG type Ii. Raised serum CK levels can be observed in both cases $^{2,43}$.

\section{Deficiency of GMPPB}

GMPPB gene (3p21.31) mutations have recently been described as a cause of autosomal recessive CMS. Cases present with a notably exclusive appendicular (mainly proximal) weakness phenotype without facial and eye muscle involvement. They also present with typical myopathic changes in different laboratory evaluations, including high serum creatine kinase levels and unspecific myopathic changes in muscle biopsy and muscle MRI studies $^{39}$. Mutations in this same gene also give rise to a broad clinical spectrum with congenital muscular dystrophies from the dystroglycanopathy family, including allelic 
conditions such as autosomal recessive congenital muscular dystrophies from the dystroglycanopathy group (types A, B and C). Despite its rarity, GMPPB-related myasthenic syndromes should be considered in the setting of a nearly proximal appendicular myopathic patient in whom therapeutic strategies have failed or clinical outcomes have unexpectedly worsened ${ }^{39}$.

\section{Other myasthenic syndromes}

\section{PREPL Deletion Syndrome (OMIM \#606407)}

The PREPL (prolyl endopeptidase-like) protein, coded by the PREPL gene (2p21), is an essential activator of clathrin adapter protein associated with type 1 (AP1), involved in vesicular transport and filling with acetylcholine and other neurotransmitters. The hypotonia-cystinuria syndrome is caused by deletions in the $S L C 3 A 1$ gene and recessive mutations in the PREPL gene, originating cystinuria type A, deficiency of growth hormone, ptosis, and limb, facial and bulbar weakness, and neonatal hypotonia. The symptoms are moderate and transiently responsive to pyridostigmine during childhood ${ }^{2,4,44}$.

\section{Deficiency of plectin}

Mutations in the PLEC gene (8q24.3), coding plectin 1, initiate a rare complex spectrum of clinical manifestations, involving epidermolysis bullosa simplex with nail dystrophy, limb-girdle muscular dystrophy type $2 \mathrm{Q}$ and congenital myasthenic syndrome. The neuromuscular phenotypes develop in patients with epidermolysis bullosa in childhood that, in the course of life, evolves into a progressive proximal myopathic phenotype refractory to pyridostigmine and decremental response pattern in neurophysiological studies ${ }^{2,45}$.

\section{Defects in sodium channels (SCN4A) (OMIM \#614198)}

An extremely rare form of CMS (less than $0,5 \%$ of all cases) was originally associated with a 20-year-old female patient with brief and abrupt attacks of muscle weakness (including bulbar palsy) and respiratory failure from birth that led to hypoxic-ischemic encephalopathy resulting from Val1442Glu mutation in the SCN4A gene (17q23.3), resulting in dysfunction of neuromuscular transmission in the unexcitability rest state $^{3,45}$. Each acute attack typically lasts from three to 30 minutes, similar to choline acetyltransferase deficiency. Allelic conditions include hyperkalemic periodic paralysis type 2 , hypokalemic periodic paralysis type 2 , atypical acetazolamide-responsive myotonia congenita and paramyotonia congenita ${ }^{4,46}$.

\section{Congenital myopathies with secondary defects of neuromuscular transmission}

Congenital myopathies represent an extremely rare cause of congenital myasthenic syndrome-like phenotype (less than $0,5 \%$ of all causes). There are several reports in the literature of congenital myopathies with mutations that can lead to secondary impairment of the neuromuscular junction from school age to young adult, notably MTM1 (coding myotubularin, Xq28), RYR1 (coding ryanodine receptor 1, 19q13.2), DNM2 (coding dynamin 2, 19p13.2), TPM3 (coding tropomyosin 3, 1q21.3) and BIN1 (coding bridging integrator 1 or amphiphysin II, 2q14.3). This results in variable combinations of myasthenic syndrome (with ptosis, ophthalmoparesis and facial paresis), exercise intolerance, variable partial responsiveness to piridostigmin or corticosteroids (especially in centronuclear myopathies) and variable decremental responses (19-35\% from baseline) or non-existent response in neurophysiological studies. Muscle biopsy in such cases usually shows atrophy of type 1 fibers with occasional loss of mitochondria and central myofibrillar degeneration ${ }^{2,3,47}$. It is essential to highlight that most genes related to these phenotypes are involved with different neuromuscular phenotypes, including nemaline myopathy, centronuclear myopathy, CAP myopathy, fiber-type disproportion congenital myopathy, lethal congenital contracture syndrome type 5 and CharcotMarie-Tooth disease spectrum.

\section{Mutations in the SLC25A1 gene}

The SLC25A1 (solute carrier family 25, mitocondrial carrier; citrate transporter, member 1) protein mediates mitochondrial citrate/isocitrate shuttle promoting cytosolic malate re-entry into the citric acid cycle and the movement of citrate across the mitochondrial inner membrane. Mutations in the SLC25A1 gene (22q11.21) initiate cognitive impairment, myasthenic symptoms, hypoplasia of the optic nerve, corpus callosum agenesis and eventually secondary 2-hydroxyglutaric aciduria., ${ }^{2,48}$ An allelic condition includes the autosomal recessive combined D-2- and L-2hydroxyglutaric aciduria (OMIM \#615182). Thus, a CMS complex phenotype linked with different central nervous system malformations should make clinicians aware of the possibility of SLC25A1 gene mutations.

In conclusion, CMS represents a genetically heterogeneous and important differential diagnosis group of early-onset peripheral hypotonic disorders. As a potentially treatable group of neuromuscular diseases, clinicians should be aware of this possibility when facing a hypotonic baby or infant with ophthalmoparesis, eyelid ptosis, facial palsy, recurrent unprovoked apneic episodes, dysphagia, dysphonia and early-onset distal joint contractures, sometimes mimicking congenital arthrogryposis multiplex. Late-onset presentations of CMS may also be considered, especially in cases of refractory seronegative myasthenia gravis, highly suggestive phenotypes or positive family history of myasthenia. 


\section{References}

1. Berrih-Aknin S, Le Panse R. Myasthenia gravis: a comprehensive review of immune dysregulation and etiological mechanisms. J Autoimmun. 2014;52:90-100. doi:10.1016/j.jaut.2013.12.011

2. Engel AG, Shen XM, Selcen D, Sine SM. Congenital myasthenic syndromes: pathogenesis, diagnosis, and treatment. Lancet Neurol. 2015;14(4):420-34. doi:10.1016/S1474-4422(14)70201-7

3. Engel AG. Congenital myasthenic syndromes. In: Katirji B, Kaminski HJ, Ruff RL, editors. Neuromuscular disorders in clinical practice. New York: Springer; 2014. p. 1073-90.

4. Rodríguez Cruz PM, Palace J, Beeson D. Inherited disorders of the neuromuscular junction: an update. J Neurol. 2014;261(11):2234-43. doi:10.1007/s00415-014-7520-7

5. Parr JR, Andrew MJ, Finnis M, Beeson D, Vincent A, Jayawant S. How common is childhood myasthenia? The UK incidence and prevalence of autoimmune and congenital myasthenia. Arch Dis Child. 2014;99(6):539-42. doi:10.1136/archdischild-2013-304788

6. Richard P, Gaudon K, Haddad H, Ammar AB, Genin E, Bauché S et al. The CHRNE 1293insG founder mutation is a frequent cause of congenital myasthenia in North Africa. Neurology. 2008;71(24):1967-72. doi:10.1212/01.wnl.0000336921.51639.0b

7. Abicht A, Stucka R, Karcagi V, Herczegfalvi A, Horváth R, Mortier W et al. A common mutation (epsilon1267delG) in congenital myasthenic patients of Gypsy ethnic origin. Neurology 1999;53(7):1564-9. doi:10.1212/WNL.53.7.1564

8. Lorenzoni PJ, Scola RH, Kay CS, Werneck LC. Congenital myasthenic syndrome: a brief review. Pediatr Neurol. 2012;46(3):141-8. doi:10.1016/j.pediatrneurol.2011.12.001

9. Mihaylova V, Scola RH, Gervini B, Lorenzoni PJ, Kay CK, Werneck LC et al. Molecular characterisation of congenital myasthenic syndromes in Southern Brazil. J Neurol Neurosurg Psychiatry. 2010;81(9):973-7. doi:10.1136/jnnp.2009.177816

10. Conti-Fine BM, Milani M, Kaminski HJ. Myasthenia gravis: past, present and future. J Clin Invest. 2006;116(11):2843-54. doi:10.1172/JCl29894

11. Meriggioli MN, Sanders DB. Autoimmune myasthenia gravis: emerging clinical and biological heterogeneity. Lancet Neurol. 2009;8(5):475-90. doi:10.1016/S1474-4422(09)70063-8

12. Pinto WBVR, Souza PVS, Oliveira ASB. Normal muscle structure, growth, development and regeneration. Curr Rev Musculoskelet Med. 2015;8(2):176-81. doi:10.1007/s12178-015-9267-x

13. Das AS, Agamanolis DP, Cohen BH. Use of next-generation sequencing as a diagnostic tool for congenital myasthenic syndrome. Pediatr Neurol. 2014;51(5):717-20. doi:10.1016/j.pediatrneurol.2014.07.032

14. Tei S, Ishii HT, Mitsuhashi H, Ishiura S. Antisense oligonucleotidemediated exon skipping of CHRNA1 pre-mRNA as potential therapy for Congenital Myasthenic Syndromes. Biochem Biophys Res Commun. 2015;461(3):481-6. doi:10.1016/j.bbrc.2015.04.035

15. Kraner S, Laufenberg I, Strassburg HM, Sieb JP, Steinlein OK. Congenital myasthenic syndrome with episodic apnea in patients homozygous for a CHAT missense mutation. Arch Neurol. 2003;60(5):761-3. doi:10.1001/archneur.60.5.761

16. Ohno K, Tsujino A, Brengman JM, Harper CM, Bajzer Z, Udd B et al. Choline acetyltransferase mutations cause myasthenic syndrome associated with episodic apnea in humans. Proc Natl Acad Sci USA. 2001;98(4):2017-22. doi:10.1073/pnas.98.4.2017

17. Mohrmann R, de Wit H, Connell E, Pinheiro PS, Leese C, Bruns D et al. Synaptotagmin interaction with SNAP-25 governs vesicle docking, priming, and fusion triggering. J Neurosci. 2013;33(36):14417-30. doi:10.1523/JNEUROSCI.1236-13.2013

18. Shen XM, Selcen D, Brengman J, Engel AG. Mutant SNAP25B causes myasthenia, cortical hyperexcitability, ataxia, and intellectual disability. Neurology. 2014;83(24):2247-55. doi:10.1212/WNL.0000000000001079

19. Herrmann DN, Horvath R, Sowden JE, Gonzalez M, SanchezMejias A, Guan Z et al. Synaptotagmin 2 mutations cause an autosomal-dominant form of lambert-eaton myasthenic syndrome and nonprogressive motor neuropathy. Am J Hum Genet. 2014;95(3):332-9. doi:10.1016/j.ajhg.2014.08.007

20. Baker K, Gordon SL, Grozeva D, Kogelenberg M, Roberts NY, Pike $M$ et al. Identification of a human synaptotagmin-1 mutation that perturbs synaptic vesicle cycling. J Clin Invest. 2015;125(4):1670-8. doi:10.1172/JCI79765

21. Ohno K, Brengman J, Tsujino A, Engel AG. Human end plate acetylcholinesterase deficiency caused by mutations in the collagen-like tail subunit (ColQ) of the asymmetric enzyme. Proc Natl Acad Sci USA. 1998;95(16):9654-9. doi:10.1073/pnas.95.16.9654

22. Mihaylova V, Müller JS, Vilchez JJ, Salih MA, Kabiraj MM, D’Amico A et al. Clinical and molecular genetic findings in COLQ-mutant congenital myasthenic syndromes. Brain. 2008;131(3):747-59. doi:10.1093/brain/awm325

23. Lorenzoni PJ, Scola RH, Gervini BL, Kay CSK, Werneck LC. Electrophysiological study in synaptic congenital myasthenic syndrome: end-plate acetylcholinesterase deficiency. Arq Neuropsiquiatr. 2009;67(2B):502-4. doi:10.1590/S0004-282X2009000300024

24. Maselli RA, Ng JJ, Anderson JA, Cagney O, Arredondo J, Williams $C$ et al. Mutations in LAMB2 causing a severe form of synaptic congenital myasthenic syndrome. J Med Genet. 2009;46(3):203-8. doi:10.1136/jmg.2008.063693

25. Ohno K, Quiram P, Milone M, Wang HL, Harper MC, Pruitt JN 2nd et al. Congenital myasthenic syndromes due to heteroallelic nonsense/ missense mutations in the acetylcholine receptor $\varepsilon$ subunit gene: identification and functional characterization of six new mutations. Hum Mol Genet. 1997;6(5):753-66. doi:10.1093/hmg/6.5.753

26. Ohno K, Hutchinson DO, Milone M, Brengman JM, Bouzat C, Sine $\mathrm{SM}$ et al. Congenital myasthenic syndrome caused by prolonged acetylcholine receptor channel openings due to a mutation in the M2 domain of the $\varepsilon$ subunit. Proc Natl Acad Sci USA. 1995;92(3):758-62. doi:10.1073/pnas.92.3.758

27. Ohno K, Wang HL, Milone M, Bren N, Brengman JM, Nakano $S$ et al. Congenital myasthenic syndrome caused by decreased agonist binding affinity due to a mutation in the acetylcholine receptor $\varepsilon$ subunit. Neuron. 1996;17(1):157-70. doi:10.1016/S0896-6273(00)80289-5

28. Chaouch A, Müller JS, Guergueltcheva V, Dusl M, Schara U, Rakocević-Stojanović $V$ et al. A retrospective clinical study of the treatment of slow-channel congenital myasthenic syndrome. J Neurol. 2012;259(3):474-81. doi:10.1007/s00415-011-6204-9

29. Shen XM, Brengman JM, Edvardson S, Sine SM, Engel AG. Highly fatal fast-channel syndrome caused by AChR $\varepsilon$ subunit mutation at the agonist binding site. Neurology. 2012;79(5):449-54. doi:10.1212/WNL.0b013e31825b5bda

30. Nicole S, Chaouch A, Torbergsen T, Bauché S, de Bruyckere E, Fontenille MJ et al. Agrin mutations lead to a congenital myasthenic syndrome with distal muscle weakness and atrophy. Brain. 2014;137(9):2429-43. doi:10.1093/brain/awu160

31. Huzé C, Bauché S, Richard P, Chevessier F, Goillot E, Gaudon K et al. Identification of an agrin mutation that causes congenital myasthenia and affects synapse function. Am J Hum Genet. 2009;85(2):155-62. doi:10.1016/j.ajhg.2009.06.015

32. Ohkawara B, Cabrera-Serrano M, Nakata T, Milone M, Asai N, Ito Ket al. LRP4 third $\beta$-propeller domain mutations cause novel congenital myasthenia by compromising agrin-mediated MuSK signaling in a position-specific manner. Hum Mol Genet. 2014;23(7):1856-68. doi:10.1093/hmg/ddt578 
33. Mihaylova V, Salih MA, Mukhtar MM, Abuzeid HA, El-Sadig SM, Hagen $M$ et al. Refinement of the clinical phenotype in musk-related congenital myasthenic syndromes. Neurology. 2009;73(22):1926-8. doi:10.1212/WNL.0b013e3181c3fce9

34. Müller JS, Herczegfalvi A, Vilchez JJ, Colomer J, Bachinski LL, Mihaylova $V$ et al. Phenotypical spectrum of DOK7 mutations in congenital myasthenic syndromes. Brain. 2007;130(6):1497-506. doi:10.1093/brain/awm068

35. Anderson JA, Ng JJ, Bowe C, McDonald C, Richman DP, Wollmann $\mathrm{RL}$ et al. Variable phenotypes associated with mutations in DOK7. Muscle Nerve. 2008;37(4):448-56. doi:10.1002/mus.20944

36. Lorenzoni PJ, Scola RH, Kay CS, Filla L, Miranda AP, Pinheiro JM et al. Salbutamol therapy in congenital myasthenic syndrome due to DOK7 mutation. J Neurol Sci. 2013;331(1-2):155-7. doi:10.1016/j.jns.2013.05.017

37. Milone M, Shen XM, Selcen D, Ohno K, Brengman J, Iannaccone ST et al. Myasthenic syndrome due to defects in rapsyn: clinical and molecular findings in 39 patients. Neurology. 2009;73(3):228-35. doi:10.1212/WNL.0b013e3181ae7cbc

38. Logan CV, Cossins J, Rodríguez Cruz PM, Parry DA, Maxwell S, Martínez-Martínez P et al. Congenital myasthenic syndrome type 19 is caused by mutations in COL13A1, encoding the atypical non-fibrillar collagen type XIII alpha-1 chain. Am J Hum Genet. 2015;97(6):878-85. doi:10.1016/j.ajhg.2015.10.017

39. Belaya K, Rodríguez Cruz PM, Liu WW, Maxwell S, McGowan $S$, Farrugia ME et al. Mutations in GMPPB cause congenital myasthenic syndrome and bridge myasthenic disorders with dystroglycanopathies. Brain. 2015;138(9):2493-504. doi:10.1093/brain/awv185

40. Selcen D, Shen XM, Milone M, Brengman J, Ohno K, Deymeer F et al. GFPT1-myasthenia: clinical, structural, and electrophysiologic heterogeneity. Neurology. 2013;81(4):370-8. doi:10.1212/WNL.0b013e31829c5e9c
41. Belaya K, Finlayson S, Slater CR, Cossins J, Liu WW, Maxwell S et al. Mutations in DPAGT1 cause a limb-girdle congenital myasthenic syndrome with tubular aggregates. Am J Hum Genet. 2012;91(1):193201. doi:10.1016/j.ajhg.2012.05.022

42. Selcen D, Shen XM, Brengman J, Li Y, Stans AA, Wieben E et al. DPAGT1 myasthenia and myopathy: genetic, phenotypic, and expression studies. Neurology. 2014;82(20):1822-30. doi:10.1212/WNL.0000000000000435

43. Cossins J, Belaya K, Hicks D, Salih MA, Finlayson S, Carboni $\mathrm{N}$ et al. Congenital myasthenic syndromes due to mutations in ALG2 and ALG14. Brain. 2013;136(3):944-56. doi:10.1093/brain/awt010

44. Régal L, Shen XM, Selcen D, Verhille C, Meulemans S, Creemers JW et al. PREPL deficiency with or without cystinuria causes a novel myasthenic syndrome. Neurology. 2014;82(14):1254-60. doi:10.1212/WNL.0000000000000295

45. Selcen D, Juel VC, Hobson-Webb LD, Smith EC, Stickler DE, Bite AV et al. Myasthenic syndrome caused by plectinopathy. Neurology. 2011;76(4):327-36. doi:10.1212/WNL.0b013e31820882bd

46. Tsujino A, Maertens C, Ohno K, Shen XM, Fukuda T, Harper CM et al. Myasthenic syndrome caused by mutation of the SCN4A sodium channel. Proc Natl Acad Sci USA. 2003;100(12):7377-82. doi:10.1073/pnas.1230273100

47. Rodríguez Cruz PM, Sewry C, Beeson D, Jayawant S, Squier W, McWilliam R et al. Congenital myopathies with secondary neuromuscular transmission defects: a case report and review of the literature. Neuromuscul Disord. 2014;24(12):1103-10. doi:10.1016/j.nmd.2014.07.005

48. Edvardson S, Porcelli V, Jalas C, Soiferman D, Kellner Y, Shaag A et al. Agenesis of corpus callosum and optic nerve hypoplasia due to mutations in SLC25A1 encoding the mitochondrial citrate transporter. J Med Genet. 2013;50(4):240-5. doi:10.1136/jmedgenet-2012-101485 